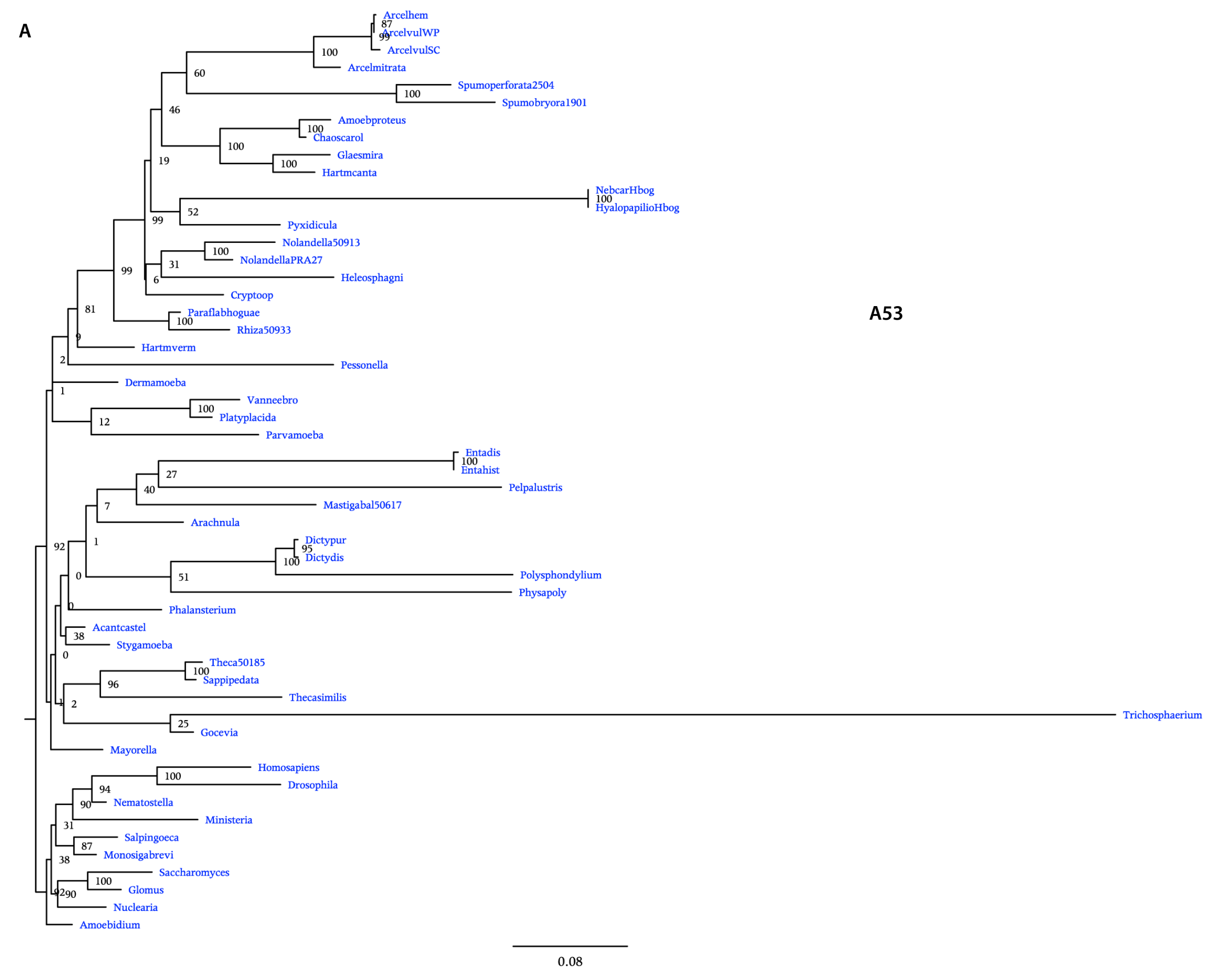




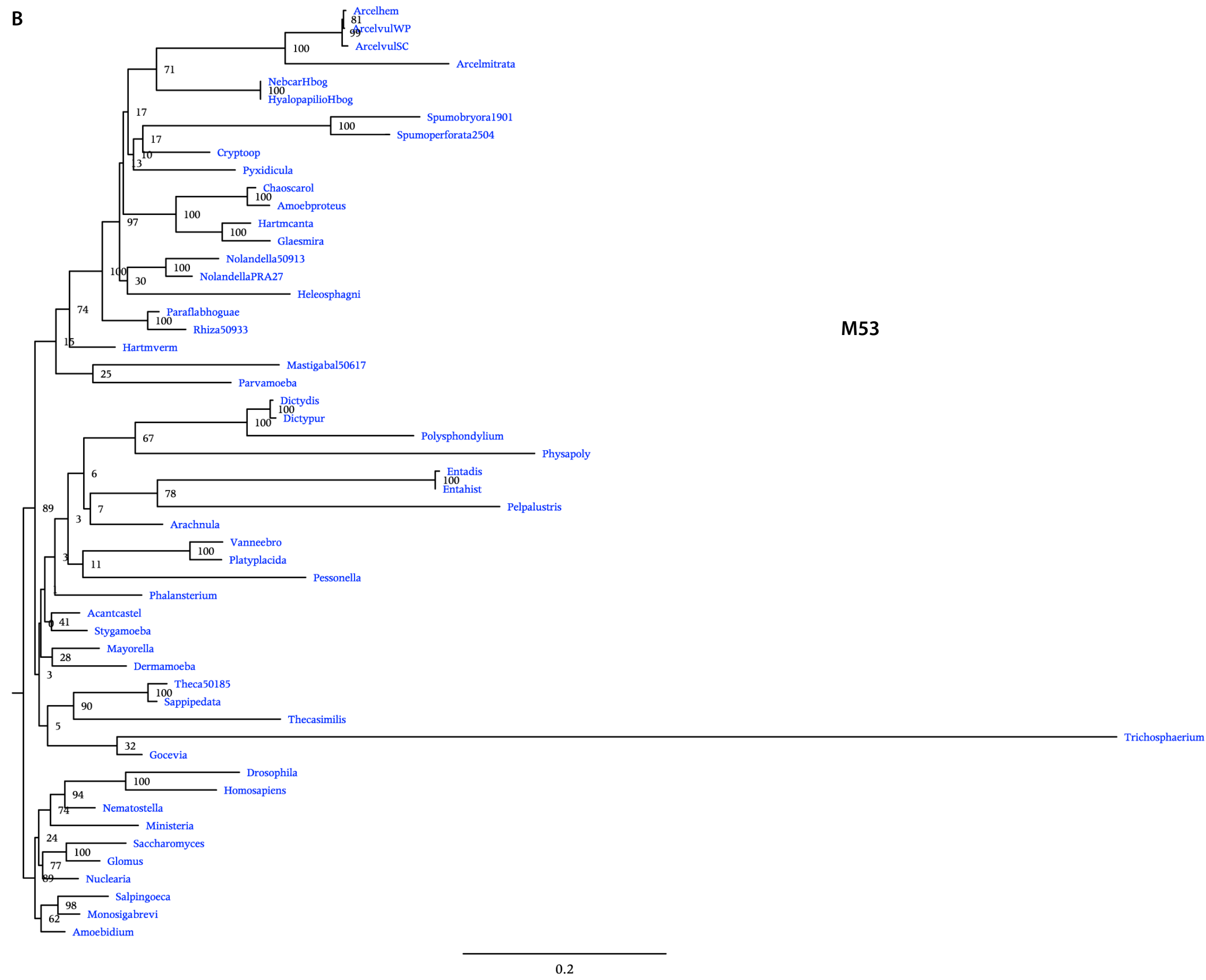



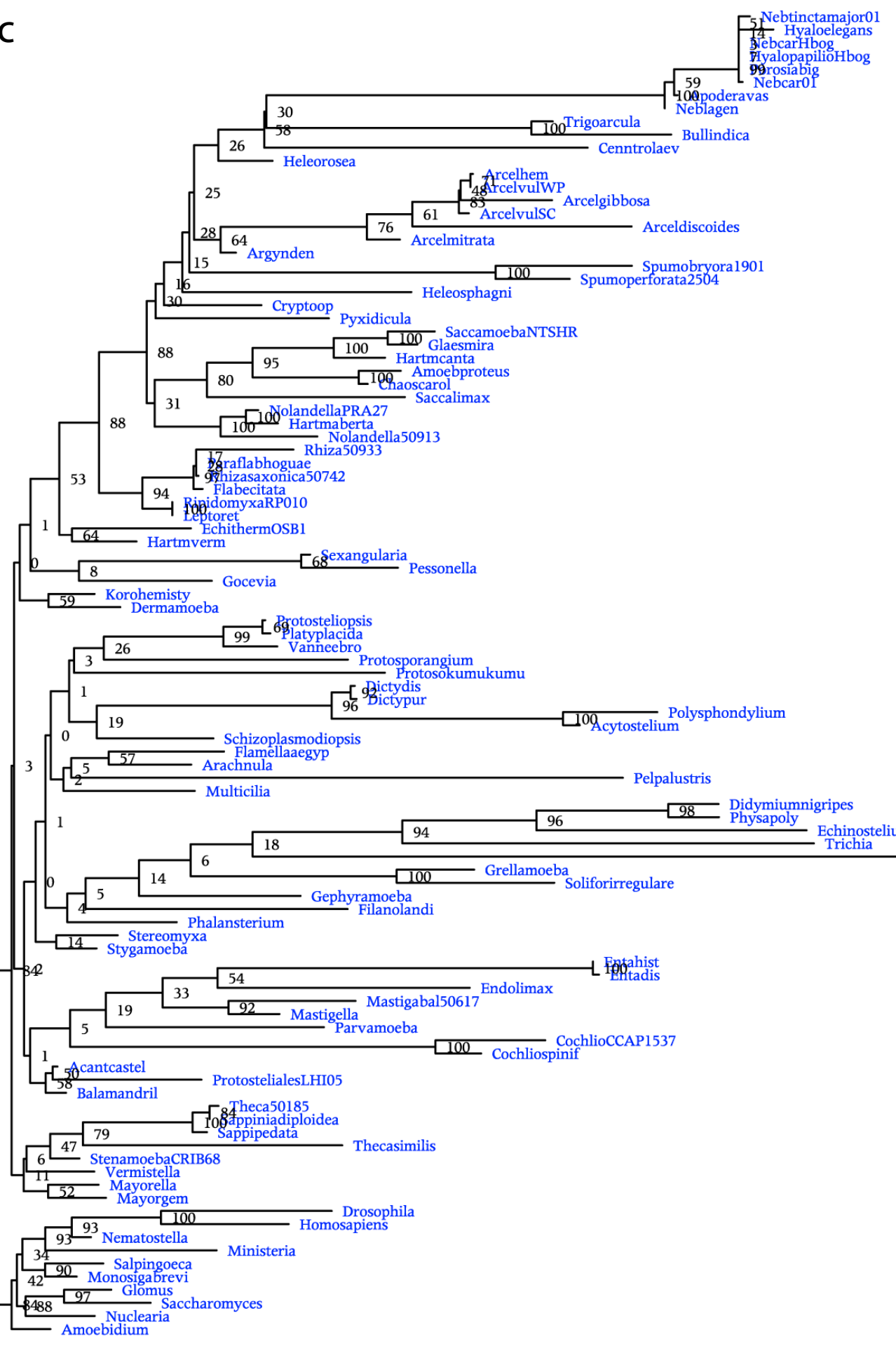


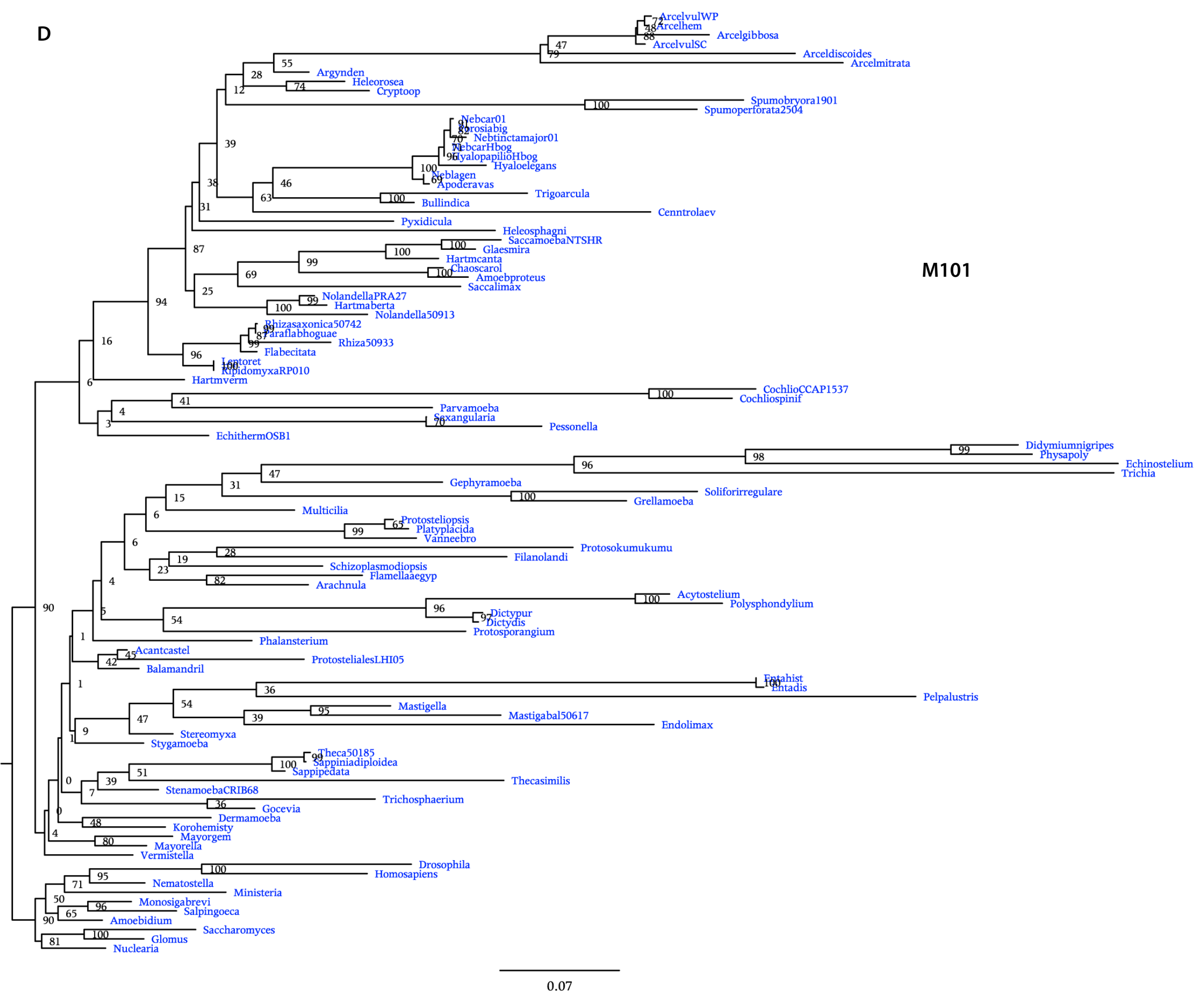




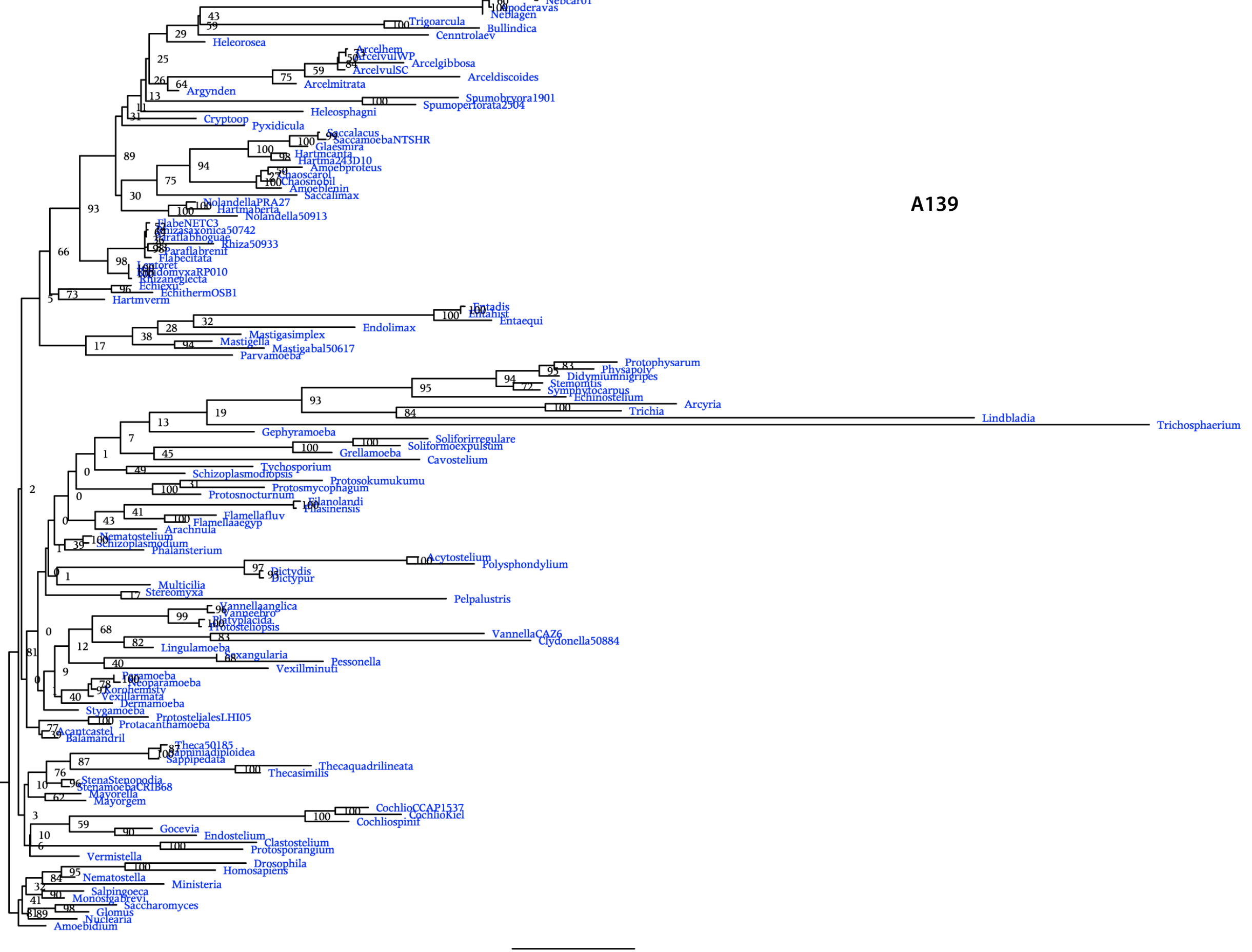




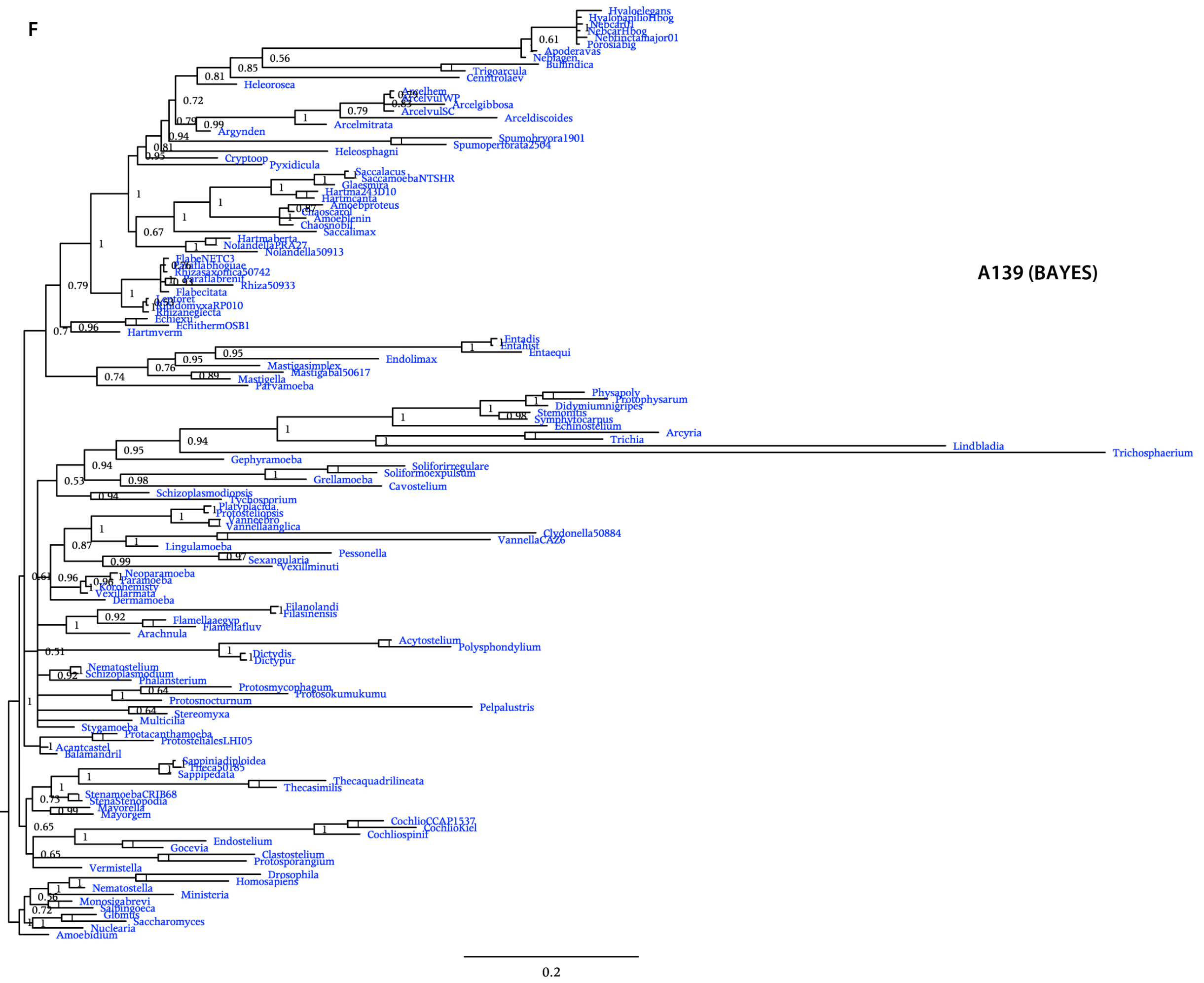




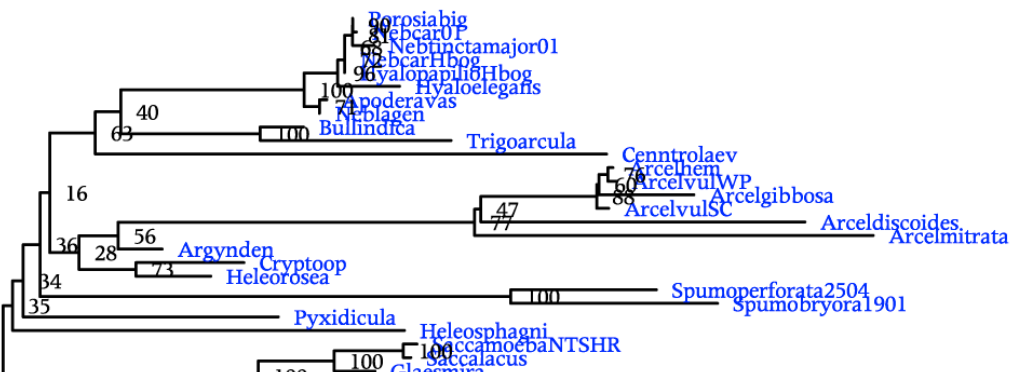

100

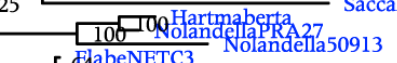

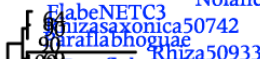

60

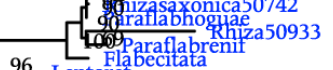

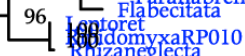

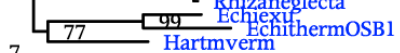

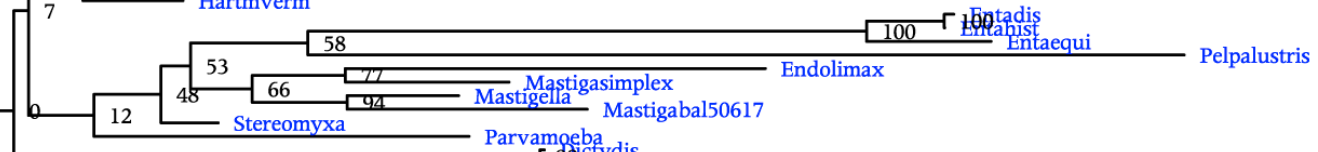

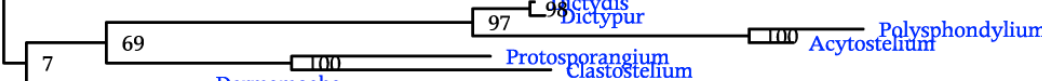

Cavestelium

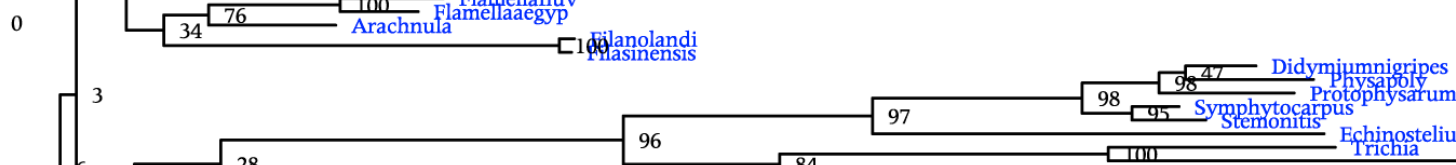

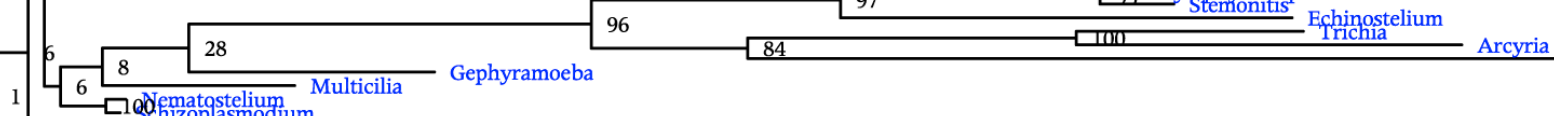

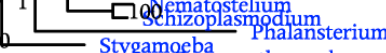

ProtostelialesLHI05

Acalamandr

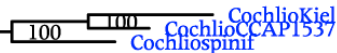

$35 \square 83-$ Gocevia Endostelium

4 Trichosphaerum Pessonella

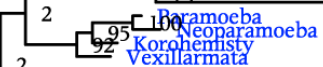

${ }^{2}$ vexillarmata 29 dynnellaanglica

DannellacAZ6

0 - Vermistella
Mayorefliagem

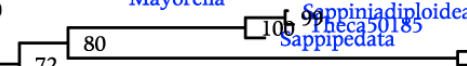

72 Thecasimilis

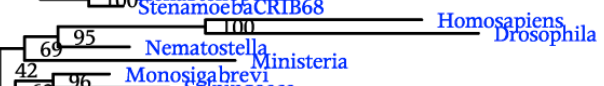

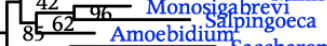

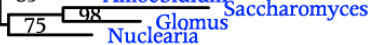




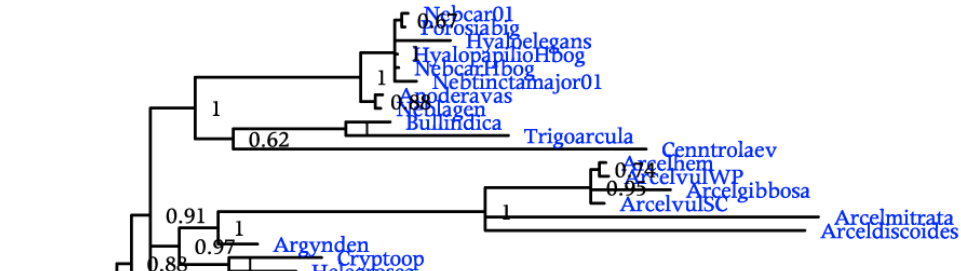

Arcelmitrata
Arceldiscolde

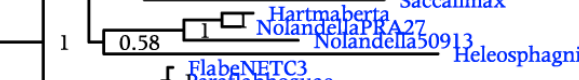

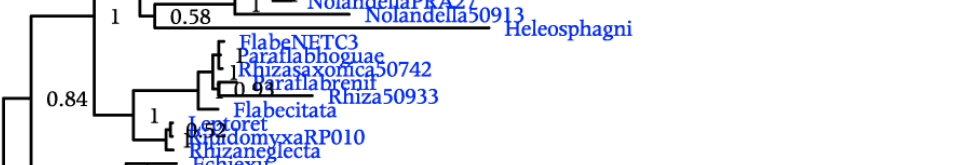

\section{M139 (BAYES)}

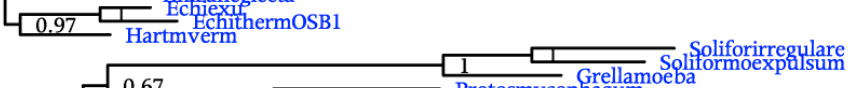

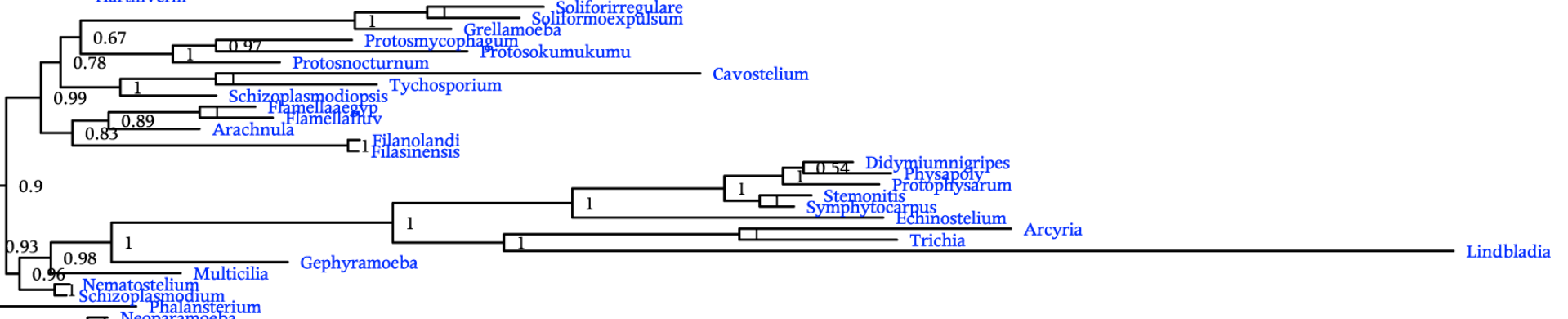

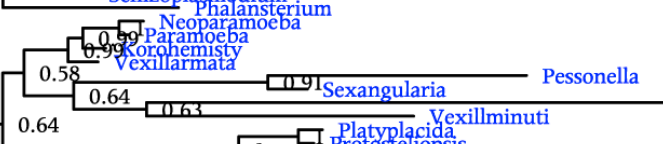

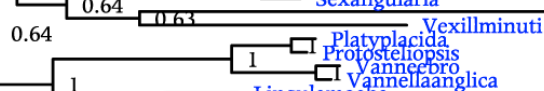

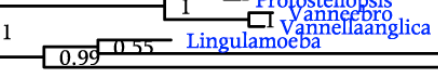

$0.540 .58 \square 088-$ Mastigella Masimplex 1 Mastgabal50617

0.81

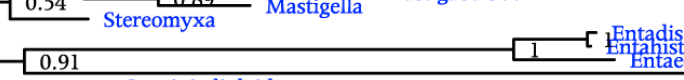

\begin{tabular}{ll}
\hline Sappipedata \\
L Thecasimilis
\end{tabular}

12
1 Stenastenopodia

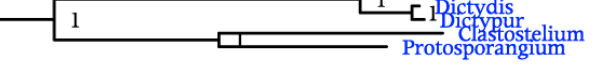

0.51 Cos8 Gocevia Endostelium

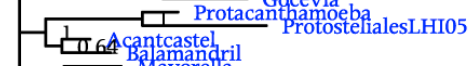

0085 M Mporela

- Stygamoeba Yemamoeba

- Nematostella

Amoebidiuspingoeca

0.95 Nuclearia 


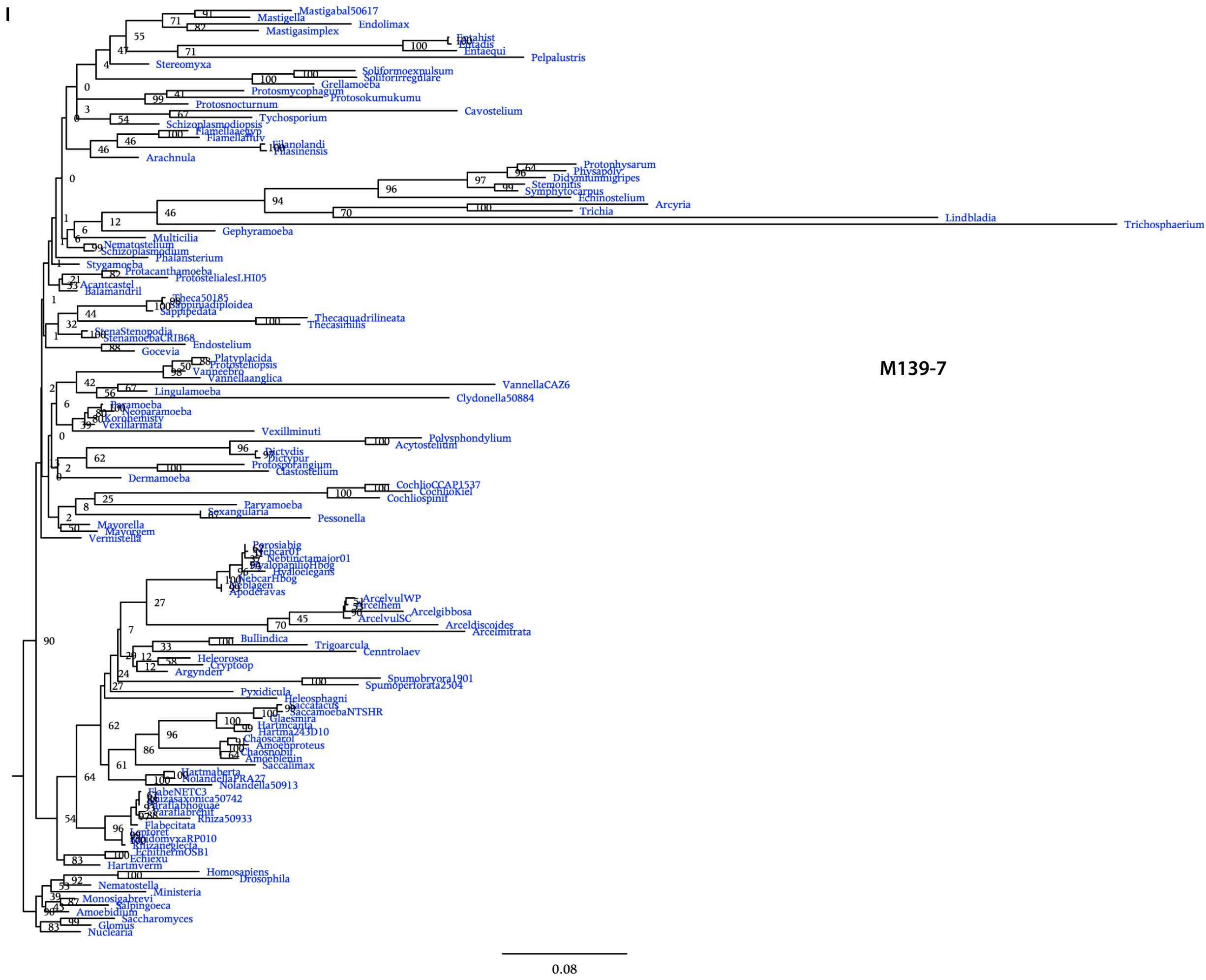




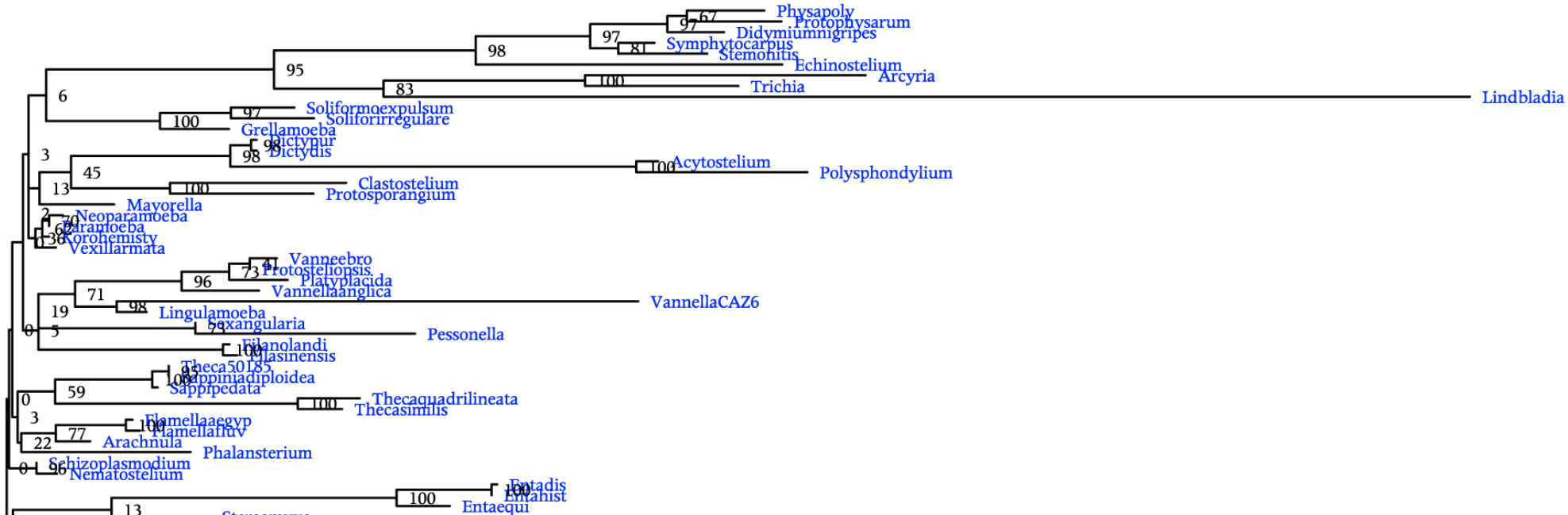

$0-13$ Stereomyxa 100

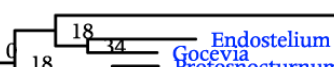
$100 \quad$ Con Cochlioccap1537

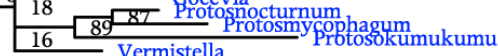

Dormistellas

G 7 Ty 31 chosporium

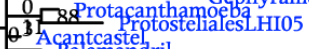

- Balamandril

Stygamoeba Parvamoeba Mastigasimplex

1 Mayogem vexillminuti

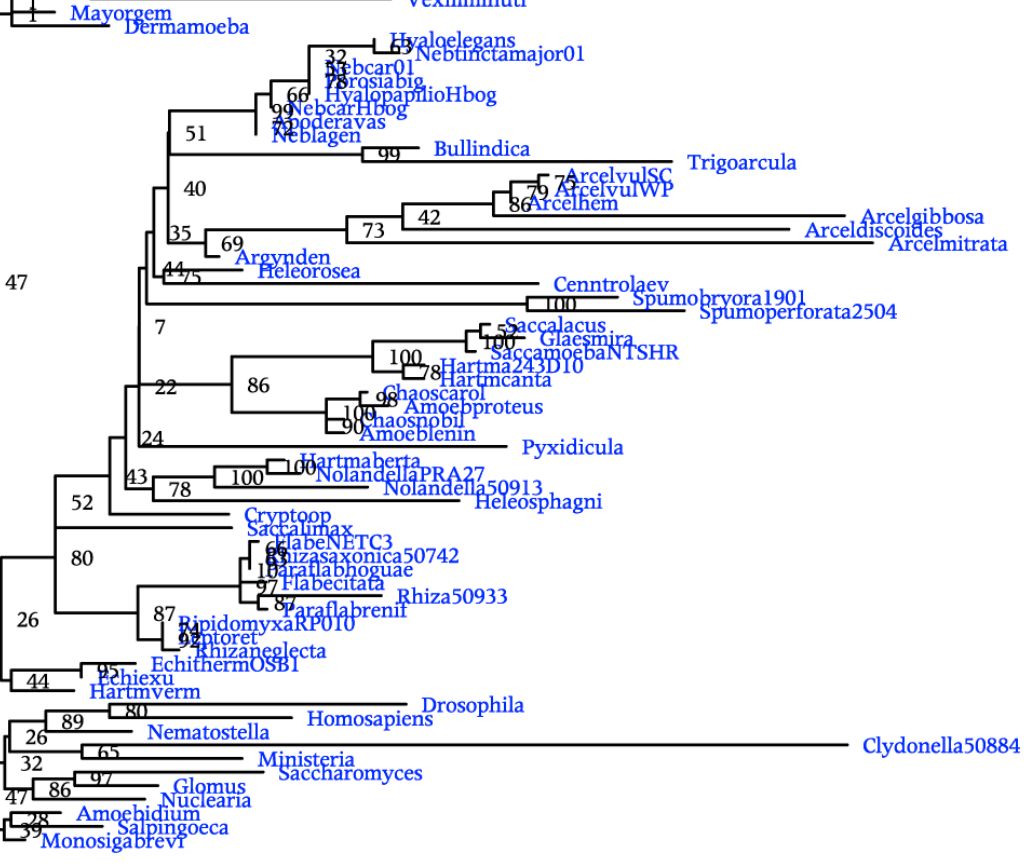

4- Mayofgem Fermamoeba Hyalgelegans 


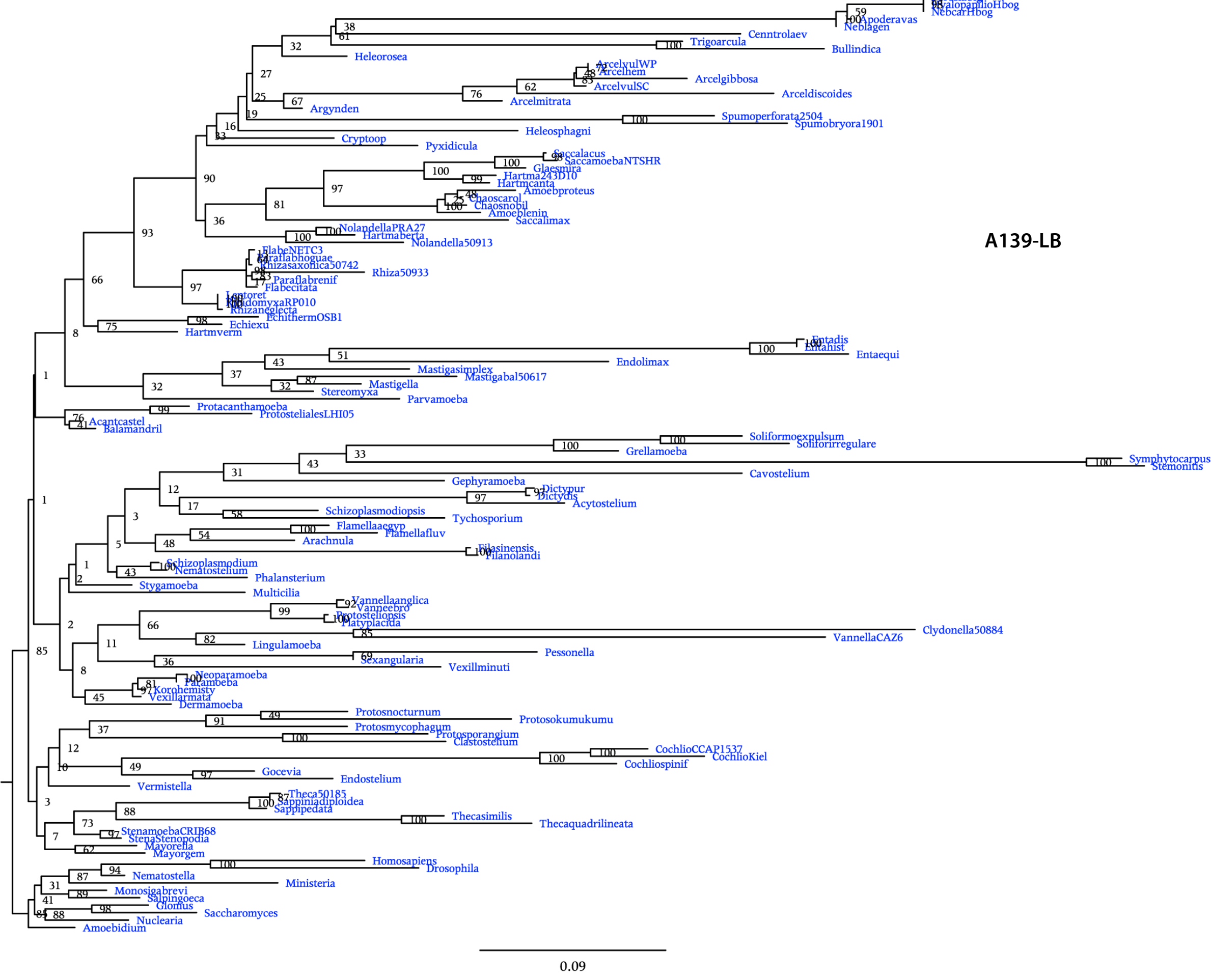




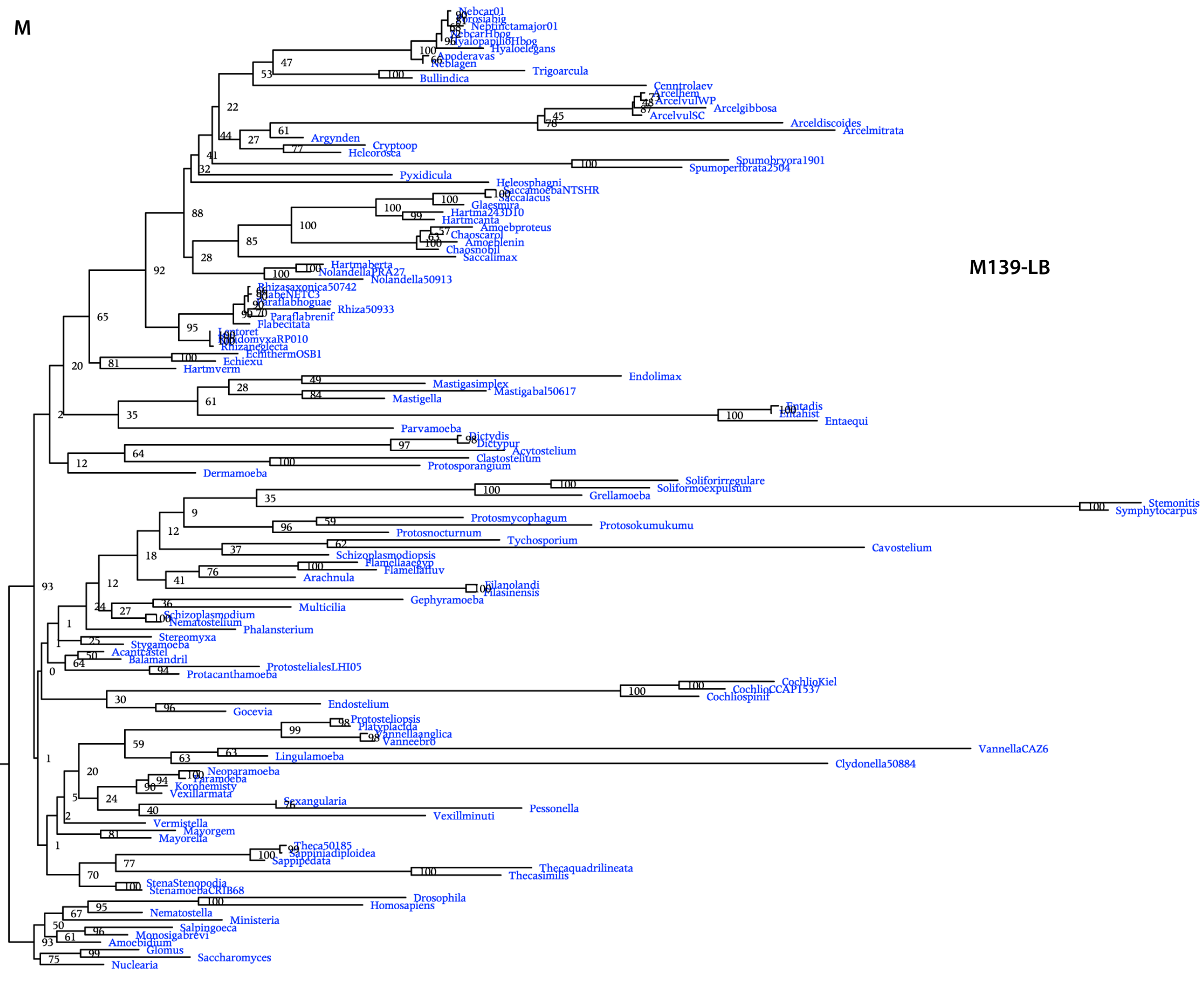




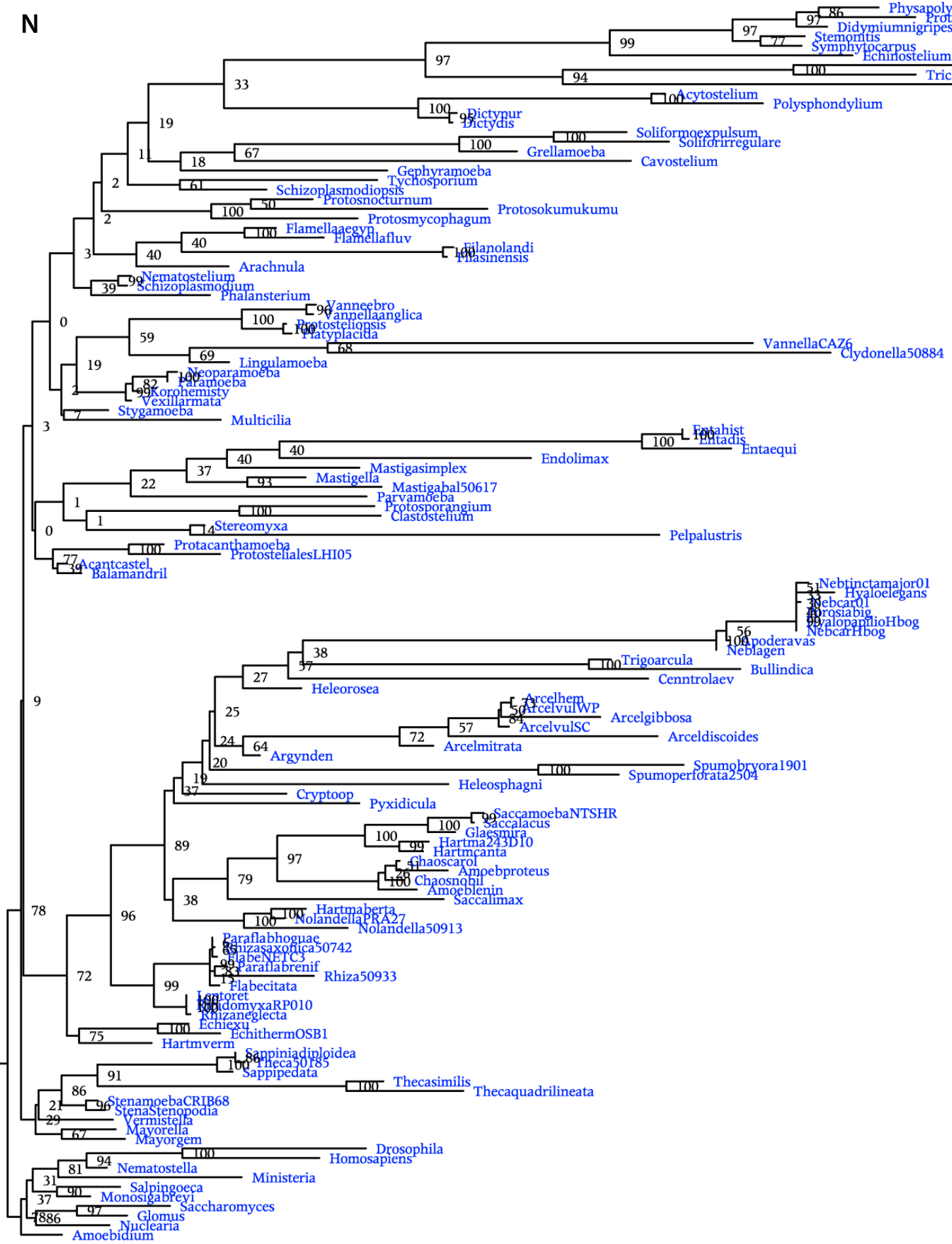




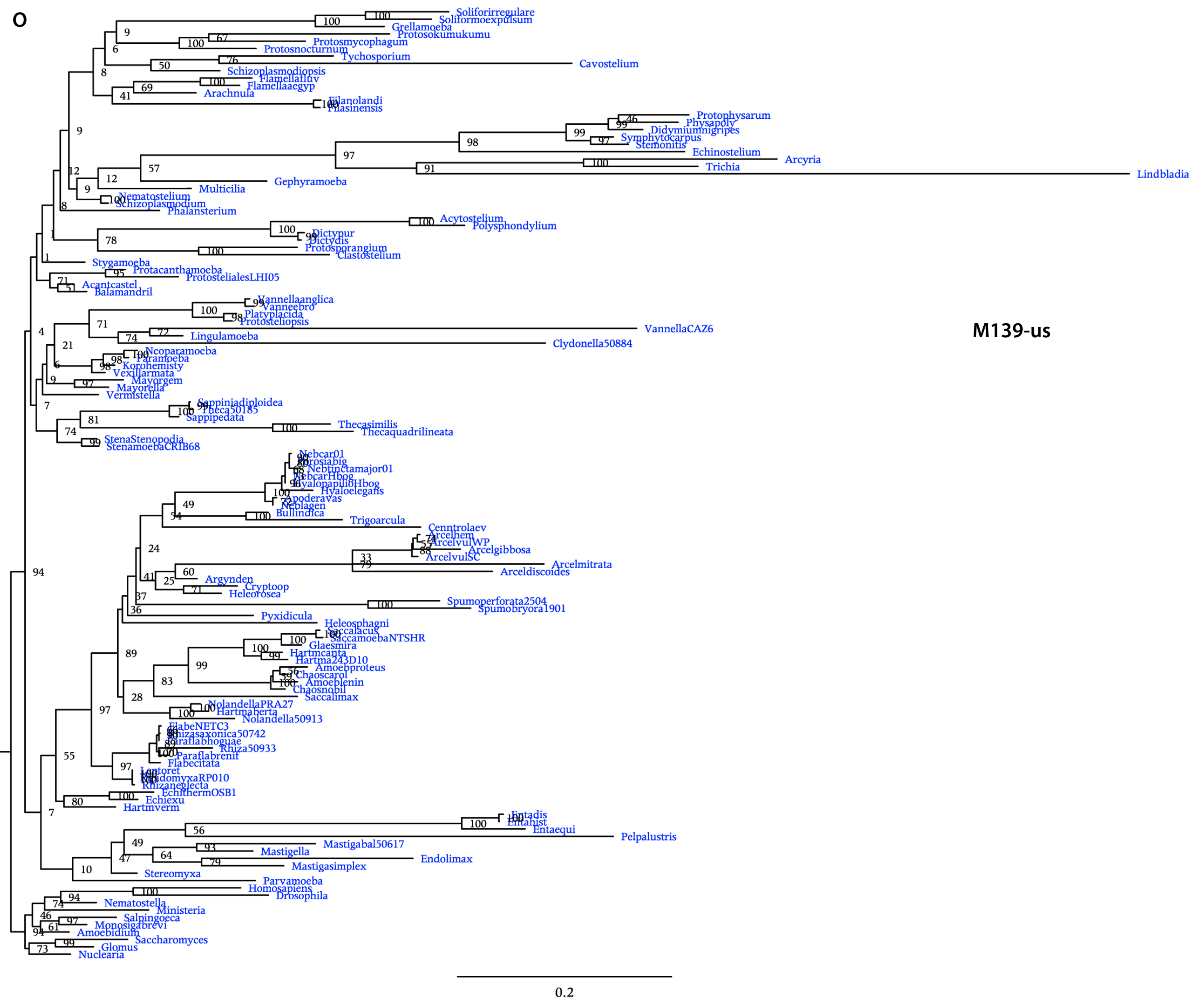




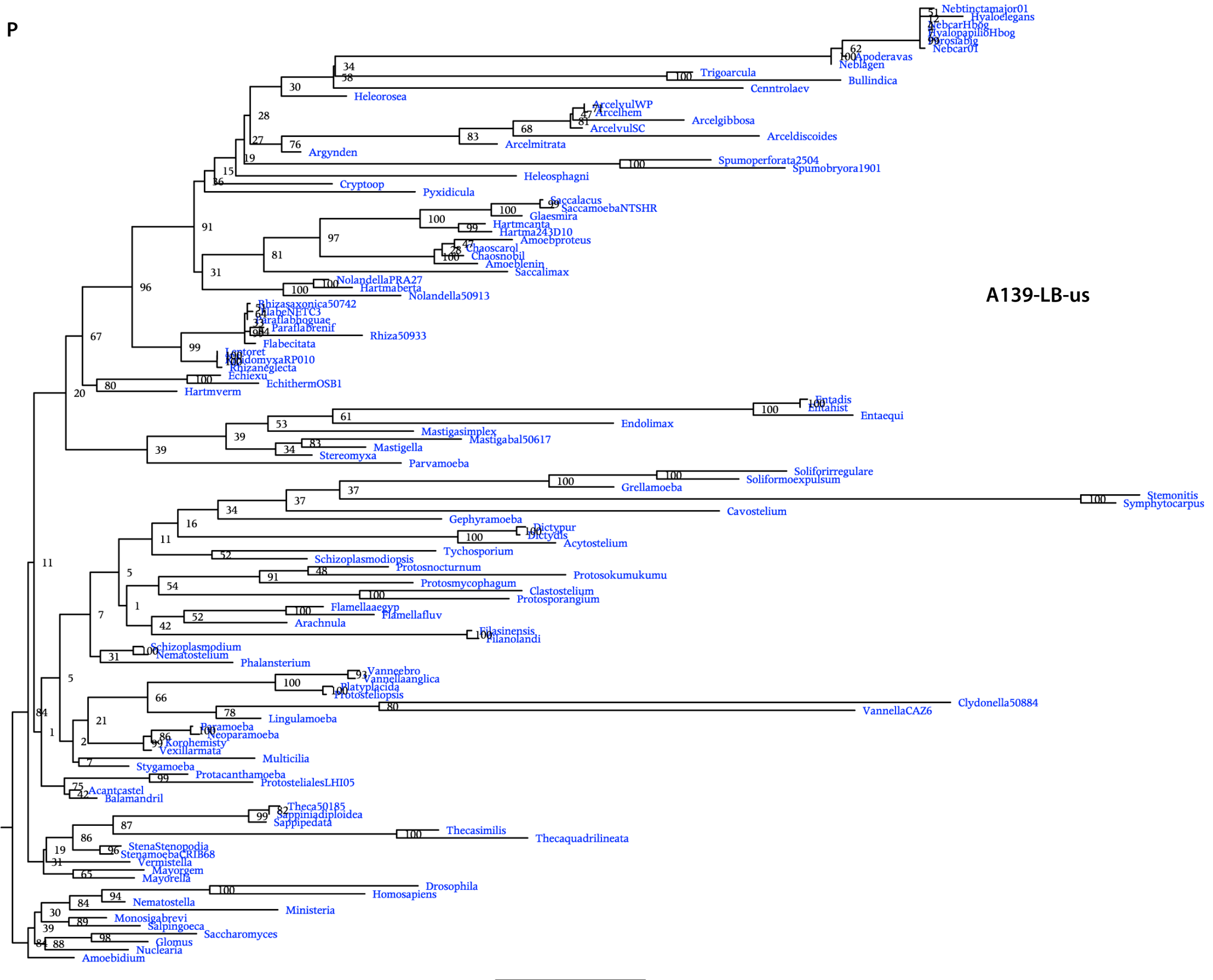




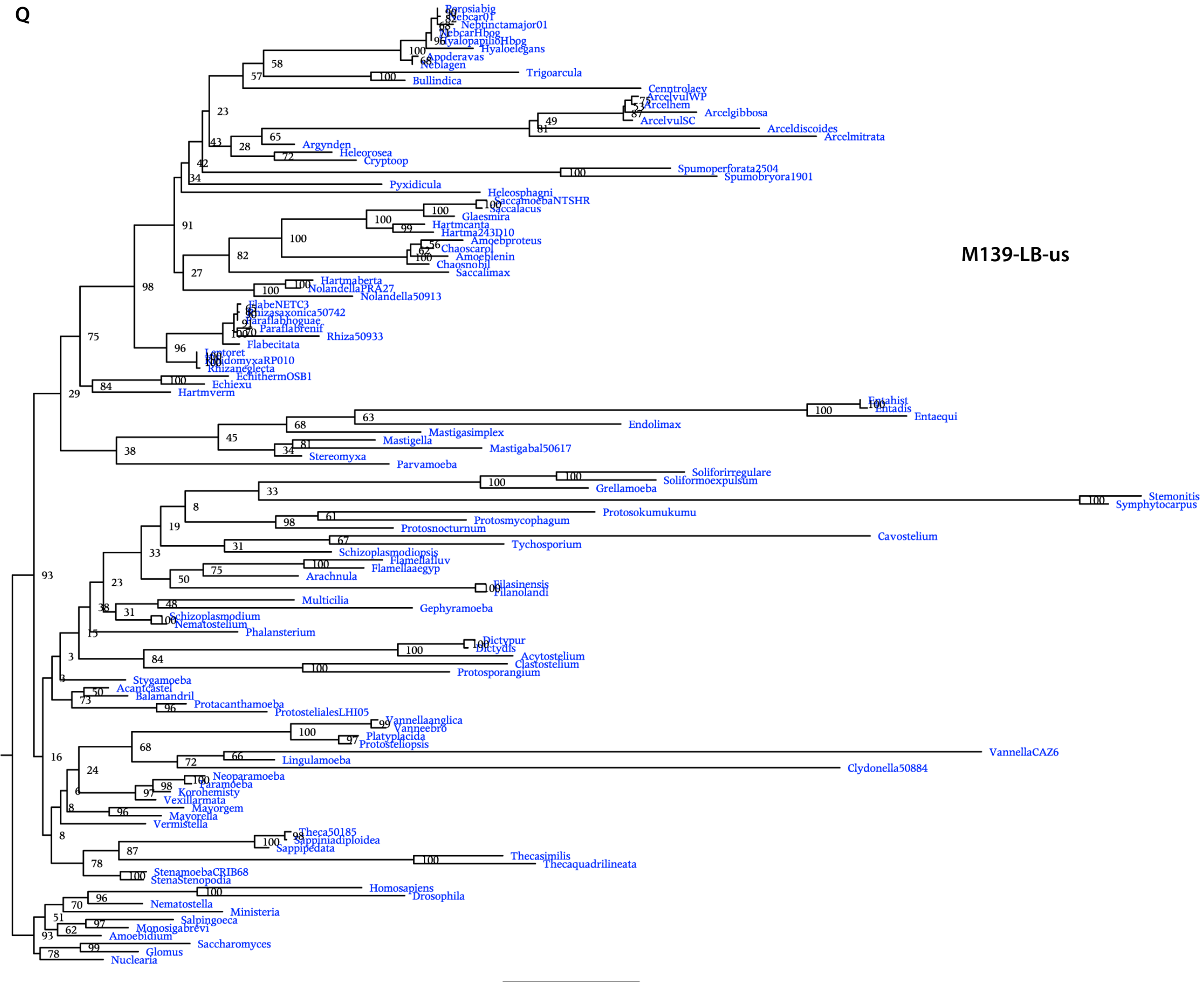




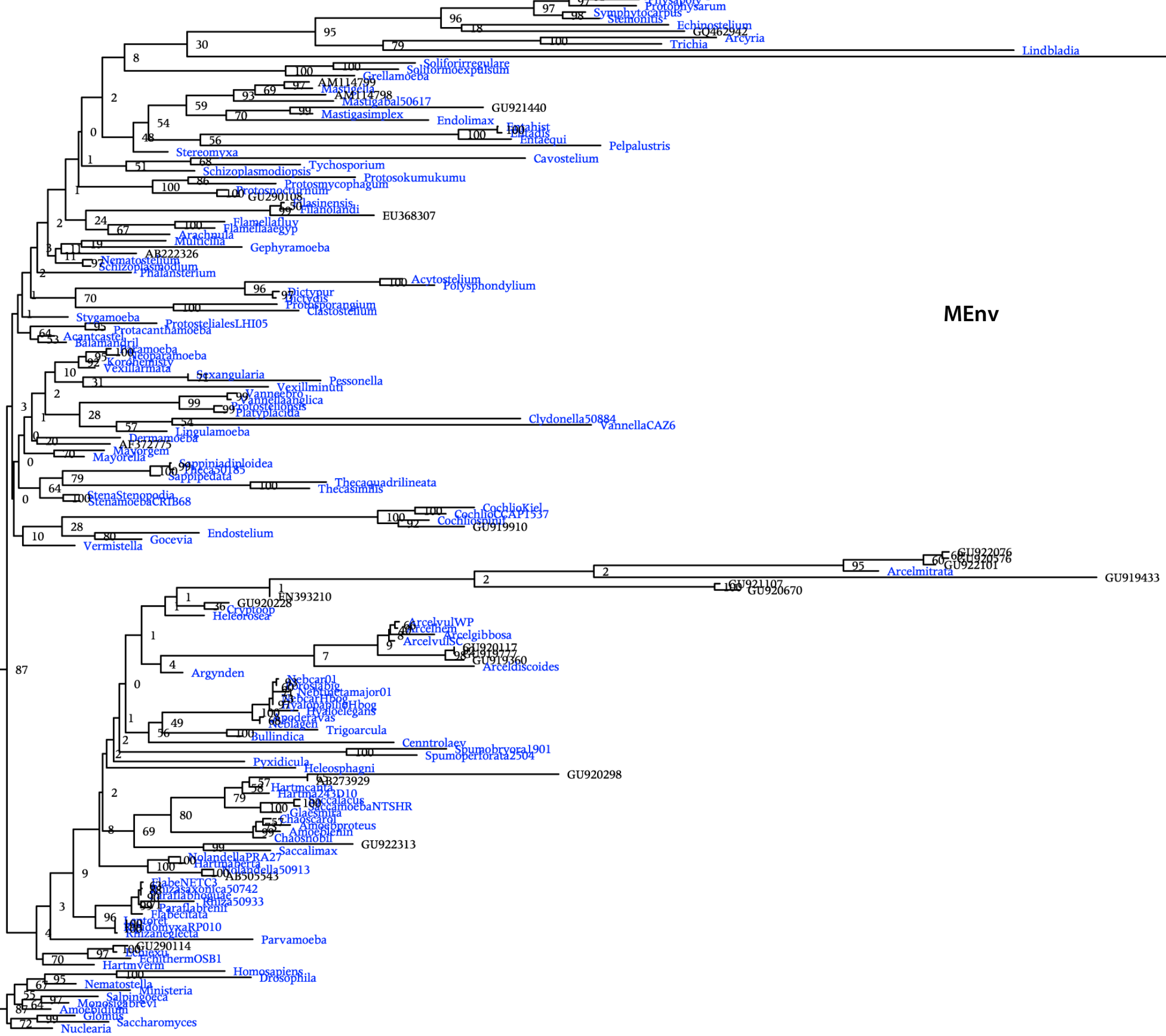

\section{MEnv}

